\title{
Acetylation of glycerol over bimetallic Ag-Cu doped rice husk silica based biomass catalyst for bio-fuel additives application
}

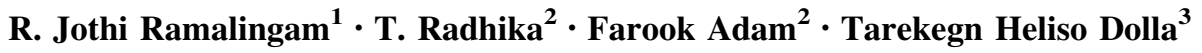

Received: 25 June 2015/Accepted: 25 January 2016/Published online: 1 March 2016

(c) The Author(s) 2016. This article is published with open access at Springerlink.com

\begin{abstract}
Acetylation of glycerol with acetic acid was carried out over bimetallic silver and copper deposited rice husk silica-alumina like ecofriendly green catalyst. Bioadditive like mono, di and tri acetyl glycerol synthesis from raw glycerol (one of the main product of biodiesel), which are gaining attention as additives for improving petroleum fuel properties towards biofuel additive development applications. Advantage of using bimetallic catalyst for glycerol acetylation due to possible synergistic effect between the metals and it enhances the catalytic conversion and selectivity compared to single metal catalyst. The prepared catalysts were characterised by XRD, FT-IR and TEM. Silver and copper incorporated RHS (rice husk silica)-alumina catalysts are shown higher activity and selectivity towards diacetin (di acetyl glycerol) and triacetins (tri acetyl glycerol) formation by catalytic acetylation of glycerol. Higher conversion (98\%) and good selectivity $(51 \%)$ is achieved.
\end{abstract}

Keywords Glycerol · Acetylation - Silver - Rice husk silica $\cdot$ Monoacetin $\cdot$ Triacetin $\cdot$ Biodiesel

R. Jothi Ramalingam

rjothiram@gmail.com

1 Surfactants research chair, Chemistry department, College of Science, King Saud University, Riyadh, Kingdom of Saudi Arabia

2 School of Chemical Sciences, Universiti Sains Malaysia, Penang 11800, Malaysia

3 College of Natural and Computational Sciences, Wolaita Sodo University, Wolaita Sodo, Ethiopia

\section{Introduction}

Glycerol is a valuable by product during biodiesel production (10\% in weight). The utilization of glycerol for the synthesis of value added chemical is a topic of great industrial interest because glycerol can be formed in large amounts during the biodiesel production and represents as a waste byproduct. Its effective utilization will be a key factor that can promote biodiesel commercialization and further development. One of the most attractive outlets of glycerol is to produce glycols especially propanediols by selective hydrogenolysis of glycerol [1,2]. This process provides a clean and economically competitive route for the production of these commodity chemicals from renewable glycerol instead of nonrenewable petroleum products. Consequently, many efforts have been attempted to facilitate this important reaction such as supported noble metals like $\mathrm{Ru}, \mathrm{Rh}$, and $\mathrm{Pt}$ are well-known active catalysts in the hydrogenolysis of glycerol [3]. Unfortunately, these catalysts are often promoting excessive $\mathrm{C}-\mathrm{C}$ cleavage, resulting in a low selectivity to propanediols. As a less expensive alternative, copper-based catalysts have been reported to have a superior performance in this reaction due to their poor activity for $\mathrm{C}-\mathrm{C}$ bond cleavage and high efficiency for $\mathrm{C}-\mathrm{O}$ bond hydro-dehydrogenation [4, 5].

Karinen and Krause reported the etherification of glycerol with isobutene over acid exchange resin catalyst $[6,7]$. Etherification of glycerol with tert-butanol over acid exchange resin or zeolite catalysts are also reported [8, 9]. Reddy et al. [10], and coworkers reported sulphated ceriazirconia and ceria alumina type solid acid catalyst for glycerol acetylation to replace mineral acid based catalyst. Bagheri and Muhd [20], reviewed the various value added product formation from glycerol by bimetallic catalysts. Hence, utilization of glycerol by acetylating agent via 
catalytic method is another alternative methodology. The present study deals with bimetallic particle doped silicaalumina type solid acid catalyst preparation and tested for glycerol acetylation. The glycerol acetylaiton products such as mono, di and triacetyl esters have great industrial applications. The triacetylated derivative is known as triacetin and has application going from cosmetics to fuel additive $[11,12]$. The mono and diacetylated esters (monoacetin and diacetin) are used in cryogenics and as raw material for production of biodegradable polyesters [13]. The aim of the present work deal with acetylation of glycerol over silver and copper incorporated rice husk silica-alumina solid acid catalyst to produce di and triacetylated glycerols with good selectivity under mild reaction conditions. The influence of various reaction parameters has also been studied.

\section{Experimental}

\section{Catalyst preparation}

Rice husk was collected from a rice mill in Penang, Malaysia. The rice husk silica was prepared by our previously reported procedure [14]. After washing and rinsing the rice husk (RH) several times with distilled water it was dried at room temperature. About $30.0 \mathrm{~g}$ of clean $\mathrm{RH}$ was stirred in $750 \mathrm{~mL}$ of $1 \mathrm{M} \mathrm{HNO}_{3}$ at room temperature for $24 \mathrm{~h}$ to remove all metallic impurities and this acid treated $\mathrm{RH}$ was washed with distilled water until the $\mathrm{pH}$ of the rinse was constant (around 4.8-5.0) and dried in an oven at $373 \mathrm{~K}$ for $24 \mathrm{~h}$, further kept in a muffle furnace at $873 \mathrm{~K}$ for $6 \mathrm{~h}$ for complete combustion. The white rice husk silica ash (RHA) thus obtained was used as source of silica for further studies.

About $10 \mathrm{~g}$ of the RHA was stirred continuously in $100 \mathrm{~mL}$ of $3 \mathrm{M} \mathrm{NaOH}$ to obtain the sodium silicate solution. To the obtained sodium silicate solution, $\mathrm{Al}\left(\mathrm{NO}_{3}\right)_{3-}$ $9 \mathrm{H}_{2} \mathrm{O} \quad(\mathrm{Si}: \mathrm{Al}=1: 1)$ and cetyl trimethyl ammonium bromide (CTAB) were added and precipitated at $\mathrm{pH}=12.3$. The solid obtained was washed, dried at $383 \mathrm{~K}$ and calcined at $873 \mathrm{~K}$. The xerogel obtained was ground to powder and labelled as RHS-Al. Similar procedure was repeated with the addition of $\mathrm{Cu}\left(\mathrm{NO}_{3}\right)_{3} \cdot 3 \mathrm{H}_{2} \mathrm{O}$ to prepare $\mathrm{Cu}(10 \mathrm{wt} \%)$ doped RHS-Al catalyst (10Cu/RHS-Al). To this system appropriate amount of $\mathrm{AgNO}_{3}$ was added and precipitated to obtain different amount of silver-copper deposited RHS-Al materials $(1 \% \mathrm{Ag}-10 \% \mathrm{Cu} / \mathrm{RHS}-\mathrm{Al}$ and $5 \% \mathrm{Ag}-10 \% \mathrm{Cu} / / \mathrm{RHS}-\mathrm{Al})$.

\section{Characterization}

The powder X-ray diffraction pattern of the catalysts was collected on Siemens Diffractometer D5000, Kristalloflex operated at $40 \mathrm{kV}$ and $10 \mathrm{~mA}$ with nickel filtered $\mathrm{CuK} \alpha$ radiation, $c=1.54 \AA$. The $\mathrm{N}_{2}$-sorption data and BET values were collected on NOVA 2200 type surface area and pore size analyzer. Pyridine adsorption analysis carried out by gaseous adsorption method using conventional hammet method. The FT-IR analysis was carried out on Perkin-Elmer System 2000 using KBr pellet method. The morphology and elemental analysis characterized by energy dispersive $\mathrm{x}$-ray spectrometry (Edax Falcon System) and transmission electron microscopy (Philips CM12).

\section{Acetylation reaction}

The acetylation of glycerol was carried out in a $50 \mathrm{~mL}$ double neck round bottom flask connected with a reflux condenser kept in an oil bath, temperature of which was controlled by a thermocouple. In a typical reaction, the catalyst powder ( $80 \mathrm{mg}$, dried at $383 \mathrm{~K}$ ), was suspended in a mixture of glycerol and acetic acid (1:10) and kept in an oil-bath at the required reaction temperature $(383 \mathrm{~K})$. The system was subjected for stirring $(700 \mathrm{rpm})$. About $5 \mu \mathrm{m}$ of solution was withdrawn at regular intervals period (30 min) and analysed by GC using toluene as an internal standard. The products were analysed on Clarus 500 (PerkinElmer) gas chromatograph with a capillary column, Elite Wax ( $30 \mathrm{~m}$ length and $0.32 \mathrm{~mm}$ inner diameter) equipped with an FID detector using toluene as the internal standard. The set temperature programme was $323 \mathrm{~K} /$ 3 min-temperature ramp of $283 \mathrm{~K} / \mathrm{min}$ to $503 \mathrm{~K}$ with $\mathrm{N}_{2}$ as carrier gas. Products were confirmed on GC-MS in Elite Wax column equipped with a mass selective detector.

\section{Results and discussion}

\section{Characterisation of $\mathrm{Ag}-\mathrm{Cu}$-silica-alumina catalysts}

The wide-angle powder X-ray diffraction pattern of as prepared catalysts with parent rice husk silica is shown in Fig. 1. The pattern depicts that RHS-Al is amorphous in nature with a broad peak in the $2 \theta$ region of $20-30^{\circ}$ at the calcination temperature of $773 \mathrm{~K}$ [16]. During copper incorporation in rice husk silica results in the formation of $\mathrm{CuO}$ nanoparticle and crystallized in monoclinic structure, which is confirmed by XRD pattern. The reflection observed at $35.5^{\circ}$ and $38.7^{\circ}$ corresponds to the formation of $\mathrm{CuO}$ nanoparticle phase formation [PDF 05-0661]. Similar observations are obtained for CuO-niobia/silica-alumina catalyst [17]. Small amount of silver particle incorporated on $\mathrm{Cu} / \mathrm{RHS}-\mathrm{Al}$ is not impact the crystal phase changes in the XRD pattern suggesting that the silver particle dispersion on the support and EDX analysis confirm the existence 


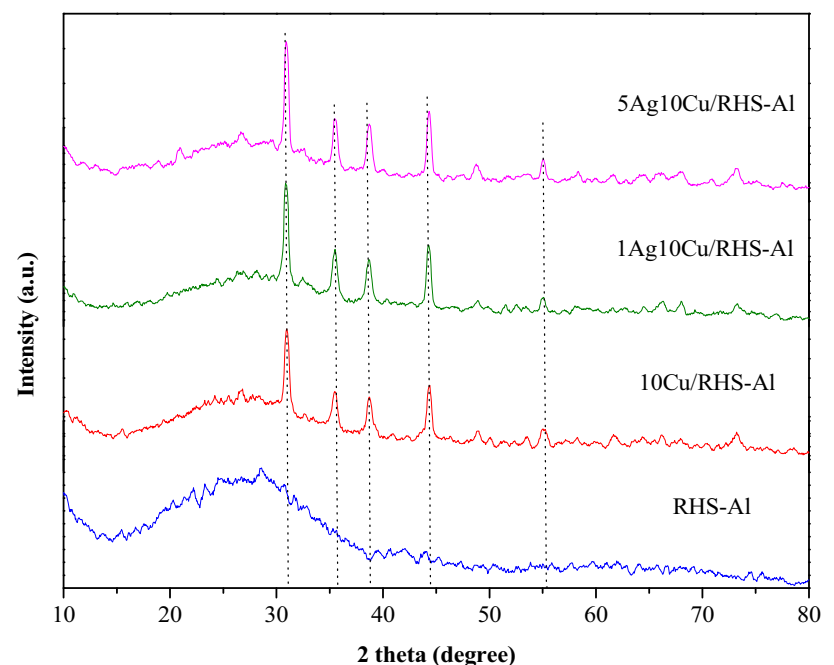

Fig. 1 The powder X-ray diffraction pattern of prepared $\mathrm{Ag}-\mathrm{Cu} /$ RHS-Al catalysts

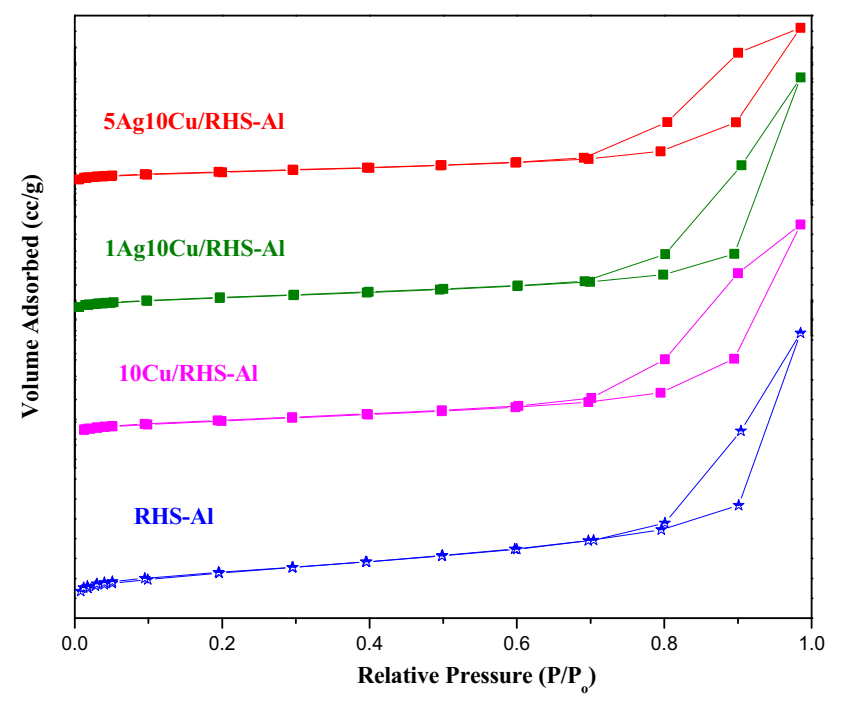

Fig. $2 \mathrm{~N}_{2}$ sorption-desorption analysis

of $\mathrm{Ag}$ and $\mathrm{Cu}$ by elemental analysis. Nitrogen adsorption and desorption study is rice husk silica and silver, copper doped rice husk silica are shown in Fig. 2. The bimetallic particle incorporated rice husk silica shown the similar characteristic curve related with micro porous structure. Figure 3 shows the FT-IR spectra of representative samples recorded at $400-4000 \mathrm{~cm}^{-1}$ rang and in all spectra, a broad absorption band appeared around $\sim 3456$ and $1635 \mathrm{~cm}^{-1}$ corresponding to the vibrations of $-\mathrm{OH}$ and silanol group $[14,15]$. The strong bands at $\sim 1011 \mathrm{~cm}^{-1}$ can be assigned to typical $\mathrm{Si}-\mathrm{O}-\mathrm{Si}$ vibration. Bands at $\sim 708$ and $452 \mathrm{~cm}^{-1}$ are due to the $\mathrm{Si}-\mathrm{O}$ vibration within $\mathrm{Si}-\mathrm{O}-\mathrm{Si}$ [14]. FT-IR spectra of samples after pyridine-adsorption

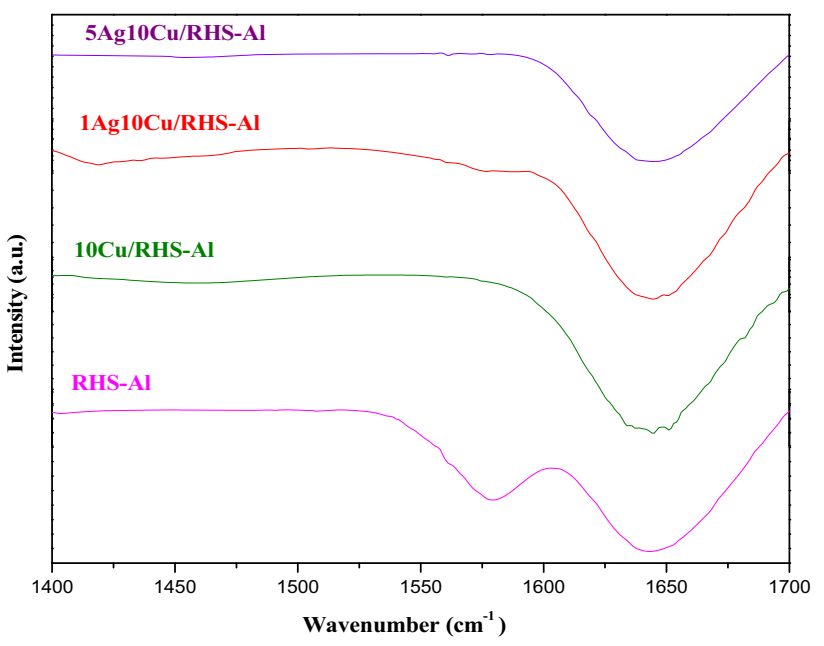

Fig. 3 FT-IR spectra of pyridine-adsorbed $\mathrm{Ag}-\mathrm{Cu} / \mathrm{RHS}-\mathrm{Al}$ catalysts

were recorded to study the nature of acidity exist in the catalyst (Fig. 3). For all catalysts, no prominent peaks were observed as seen in the spectra. In the entire sample a broad absorption band was observed at $\sim 1650 \mathrm{~cm}^{-1}$ corresponding to bronsted acid nature of the support [15]. In the case of RHS-A1 exhibits a band centred at $\sim 1575 \mathrm{~cm}^{-1}$ due to surface hydroxyl acidity. Therefore, bronsted acidity in nature exists predominantly in the as prepared $\mathrm{Ag}-\mathrm{Cu} /$ RHS-Al solid acid catalyst. Morphologies of as synthesized bimetallic $\mathrm{Cu}-\mathrm{Ag}$-rice husk silica-alumina catalyst are shown in Fig. 4. The magnification of Fig. 4a is around $5 \mu \mathrm{m}$. The SEM images shown the aggregated particle morphology for as prepared bimetallic solid acid catalyst and copper oxide nanoparticle forms the cubic shape particle on RHS-alumina support, which is shown in arrow mark in Fig. 4a. The white colour cubic particle exists on silica-alumina due to formation of crystallized copper oxide particle after calcinations process (Fig. 4b). The amount of copper and silver is further determined by elemental analysis using EDX connected with SEM equipment. Figure 5 shows the elemental composition of as prepared bimetallic rice husk silica catalyst; edx spectra confirm the copper and silver particle existence in RHS support. TEM images are also confirms the aggregated particle morphology formation for as prepared solid catalysts and the size of the particle exists in the range of $30-40 \mathrm{~nm}$ and the scale value in the TEM image is $50 \mathrm{~nm}$. The dense lengthy particle in the TEM image of Fig. $3 \mathrm{~b}$ is due to existence copper oxide nanoparticle aggregation with RHS-alumina support. The length of the dense particle is more than $50 \mathrm{~nm}$ and below $80 \mathrm{~nm}$. The pore size $\mathrm{N}_{2}$ sorption analysis shows the uniform porosity and BET surface area of $1 \mathrm{Ag}-5 \mathrm{Cu} / \mathrm{RHS}-\mathrm{Al}$ to RHS-Al are shown in Fig. 2 and Table 1. 

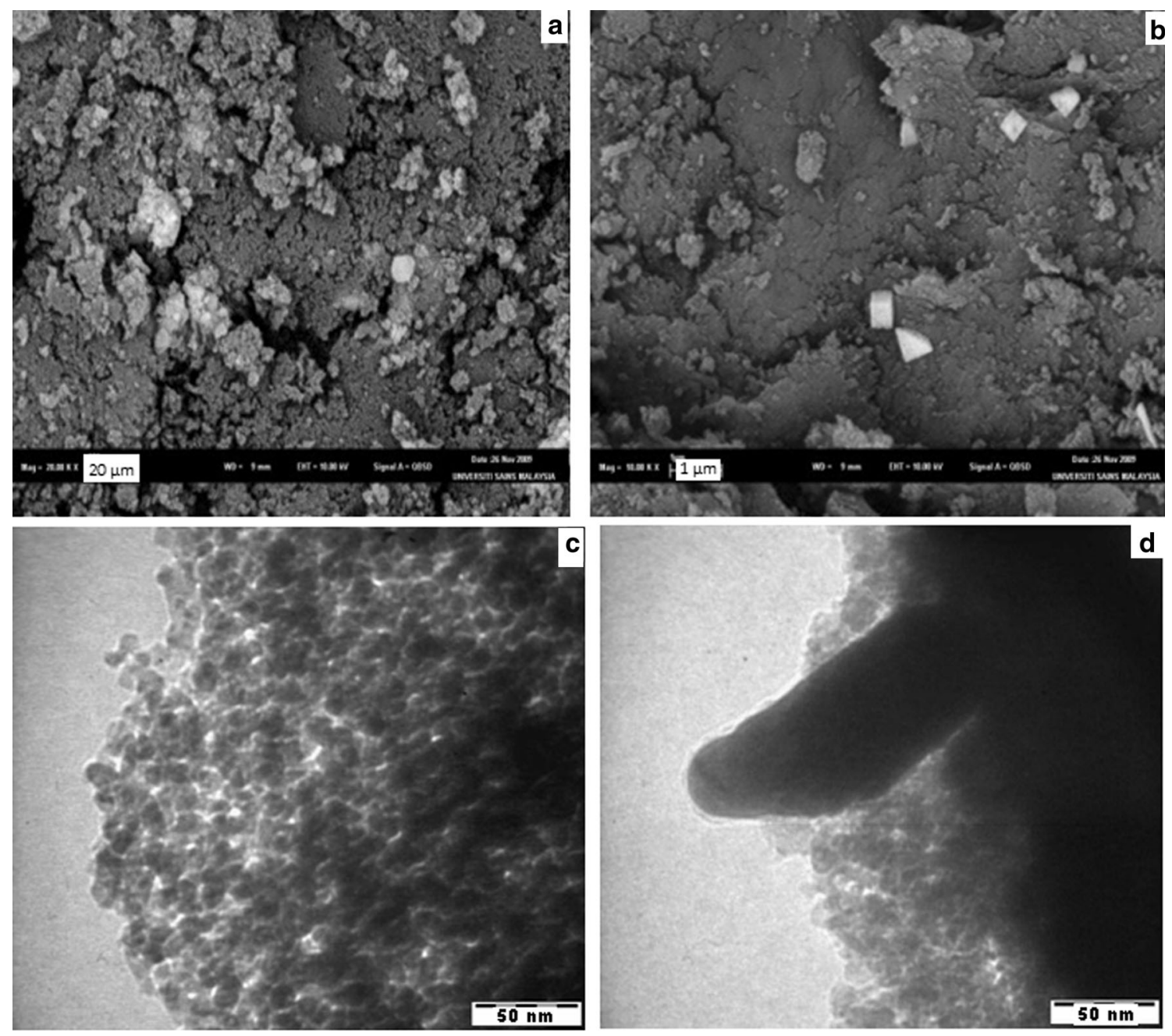

Fig. 4 SEM images of a $1 \mathrm{Ag} 10 \mathrm{Cu} / \mathrm{RHS}-\mathrm{Al} \mathbf{b} 5 \mathrm{Ag} 10 \mathrm{Cu} / \mathrm{RHS}-\mathrm{Al}$ and TEM images of $\mathbf{c} 1 \mathrm{Ag} 10 \mathrm{Cu} / \mathrm{RHS}-\mathrm{Al} \mathbf{d} 5 \mathrm{Ag} 10 \mathrm{Cu} / \mathrm{RHS}-\mathrm{Al}$

\section{Catalytic activity of $\mathrm{Cu}-\mathbf{A g}$-silica-alumina catalysts}

Acetylation of glycerol over different amount of copper and silver incorporated rice husk silica catalyst is shown in Table 2. Silver and copper incorporated in the ratio of 1:10 and the reaction carried out at various temperatures. Conversion of glycerol acetylation over $1 \mathrm{Ag}-10 \mathrm{Cu} / \mathrm{RHS}-\mathrm{Al}$ catalyst is increased upon increase with reaction temperature. At higher temperature like 383 and $393 \mathrm{~K}$ shows the maximum conversion towards glycerol derivative formation. The selectivity towards monoacetin was decreased and diacetin and triacetin formation was increased. Tiracetin formation is increased at optimized temperature range between $353-373 \mathrm{~K}$ and above $373 \mathrm{~K}$, triacetin formation was slashed. The selectivity of diacetin formation is very low at starting temperature and increased upon optimized reaction temperature. The di and tri-acetin formation was improved in the presence of bimetallic $\mathrm{Ag}-\mathrm{Cu}$ loaded silica-alumina catalyst at optimized reaction condition.

The effect of molar ratio between glycerol and acetic acid has also been studied in the presence of $1 \mathrm{Ag} 10 \mathrm{Cu}-$ silica-alumina catalyst. The results of glycerol acetylation with different mole ratio of acetic acid and glycerol were shown in Table 3. In all analysis toluene is used as internal standard for determination of glycerol conversion in GC analysis. A Table 4 show the higher amount of silver incorporation on $\mathrm{Cu} / \mathrm{RHS}-\mathrm{A} 1$ solid catalyst is increases the glycerol conversion and selectivity towards di and triacetin formation. Silver incorporation is acting as a promoter for copper-RHS-A1 catalyst and increasing the metal particle deposition results in the higher amount of glycerol conversion occurred. From Table 3, Glycerol conversion increased gradually with increased amount of acetic acid, results in the formation of higher yield of diacetin and triacetin. At higher mole ratio between glycerol/acetic acid 


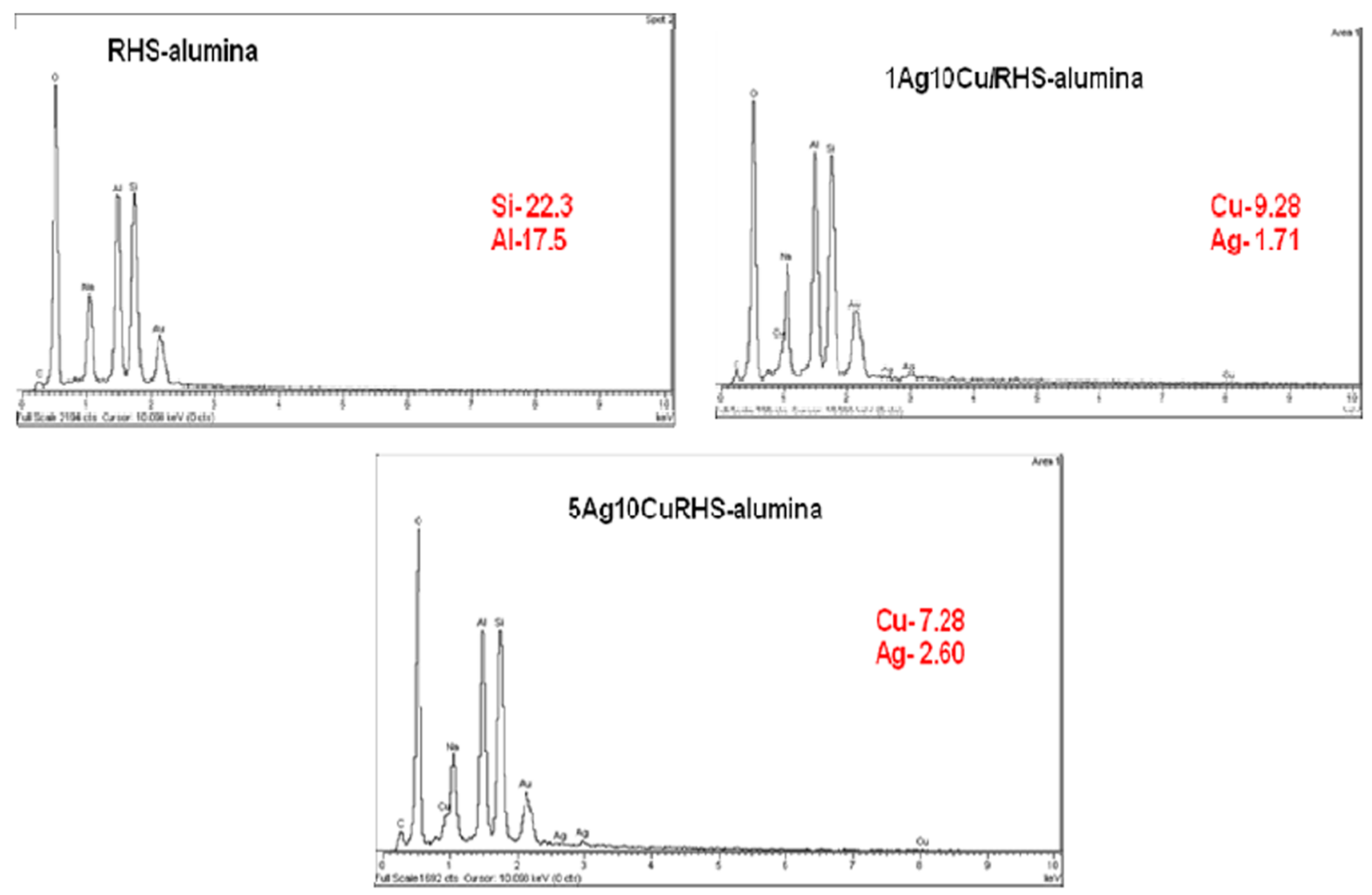

Fig. 5 EDX analysis of selected catalysts

Table 1 BET surface area of the catalysts

\begin{tabular}{lcl}
\hline Sample & BET surface area $\left(\mathrm{m}^{2} \mathrm{~g}^{-1}\right)$ & Crystallite size $(\mathrm{nm})$ \\
\hline RHS-Al & 79.4 & - \\
$10 \mathrm{Cu} / \mathrm{RHS}-\mathrm{Al}$ & 92.6 & - \\
$1 \mathrm{Ag} 10 \mathrm{Cu} / \mathrm{RHS}-\mathrm{Al}$ & 108.1 & - \\
$5 \mathrm{Ag} 10 \mathrm{Cu} / \mathrm{RHS}-\mathrm{Al}$ & 93.1 & 57.4 \\
\hline
\end{tabular}

Table 2 Influence of temperature for catalytic acetylation of glycerol

\begin{tabular}{llcll}
\hline Temperature (K) & Conversion (\%) & \multicolumn{4}{c}{ Selectivity $(\%)$} \\
\cline { 3 - 5 } & & MAG & DAG & TAG \\
\hline 333 & 69.4 & 100 & - & - \\
353 & 78.9 & 71.1 & 5.1 & 23.8 \\
373 & 80.9 & 72.8 & 2.5 & 24.6 \\
383 & 83.4 & 68.3 & 18.5 & 13.2 \\
393 & 80.5 & 65.6 & 16.8 & 17.6 \\
\hline
\end{tabular}

Reaction conditions: catalyst $=1 \mathrm{Ag} \quad 10 \mathrm{Cu} / \mathrm{RHS}-\mathrm{Al}$; catalyst weight $=80 \mathrm{mg}$; molar ratio of glycerol to acetic acid $=1: 10$; reaction time $=5 \mathrm{~h}$

is hinder the formation of monoacetin and higher selectivity obtained for triacetin formation in the presence of $\mathrm{Ag}-\mathrm{Cu}$-silica-alumina bimetallic catalyst. Table 3 shows maximum conversion ( 80.4 and $85.7 \%$ ) with the higher selectivity towards triacetin formation (30.1 and $43.2 \%)$ at increase amount of mole ratio such as 1:20 and 1:25. In eco-point of view and cost effective in large scale synthesis is optimized towards 1:10 more ratio usage of glycerol: acetic acid is the best for obtain MAG. Table 4 show the higher glycerol conversion with good selectivity at optimized glycerol and acetic acid mole ratio (1:10). Hence, bimetallic nanoparticle deposition on silica support and mole ratio variation between glycerol and acetic acid are playing important role in triacetin formation from glycerol. Addition of appropriate amount of silver and copper deposition on silica-alumina catalyst shows the considerable improvement in catalyst texture property towards high catalytic activity. The higher amount of bimetallic species incorporated catalysts $(1 \mathrm{Ag} 10 \mathrm{Cu} / \mathrm{RHS}-\mathrm{Al}$ and $5 \mathrm{Ag} 10 \mathrm{Cu} /$ 
Table 3 Effect of molar ratio of glycerol to acetic acid for acetylation of glycerol

\begin{tabular}{llllr}
\hline Molar ratio (Glycerol: & Conversion $(\%)$ & \multicolumn{3}{l}{ Selectivity $(\%)$} \\
\cline { 3 - 5 } acetic acid)/mmol & & MAG & DAG & TAG \\
\hline $1: 5$ & 76.3 & 84.8 & 12.3 & 2.9 \\
$1: 10$ & 83.4 & 68.3 & 18.5 & 13.2 \\
$1: 15$ & 81.2 & 55.3 & 28.0 & 17.7 \\
$1: 20$ & 80.4 & 43.9 & 26.0 & 30.1 \\
$1: 25$ & 85.7 & 32.5 & 24.3 & 43.2 \\
\hline
\end{tabular}

Reaction conditions: catalyst $=1 \mathrm{Ag} 10 \mathrm{Cu} / \mathrm{RHS}-\mathrm{Al}$; catalyst weight $=80 \mathrm{mg}$; temperature $=383 \mathrm{~K}$; reaction time $=5 \mathrm{~h}$
Table 4 Acetylation of glycerol with acetic acid on influence of catalyst amount

\begin{tabular}{lllll}
\hline Catalyst & Conversion (\%) & \multicolumn{3}{c}{ Selectivity $(\%)$} \\
\cline { 3 - 5 } & & MAG & DAG & TAG \\
\hline RHS & - & - & - & - \\
RHS-Al & 76.8 & 89.4 & 10.6 & - \\
$10 \mathrm{Cu} / \mathrm{RHS}-\mathrm{Al}$ & 83.8 & 68.3 & 21.1 & 10.6 \\
1Ag10Cu/RHS-Al & 97.5 & 3.7 & 58.4 & 37.9 \\
$5 \mathrm{Ag} 10 \mathrm{Cu} /$ RHS-Al & 100 & 2.4 & 46.3 & 51.3 \\
\hline
\end{tabular}

Reaction conditions: temperature $=383 \mathrm{~K} ; 1 \mathrm{Ag} 10 \mathrm{Cu} / \mathrm{RHS}-\mathrm{Al}$; catalyst weight $=100 \mathrm{mg}$; molar ratio of glycerol to acetic acid $=1: 10$; reaction time $=5 \mathrm{~h}$

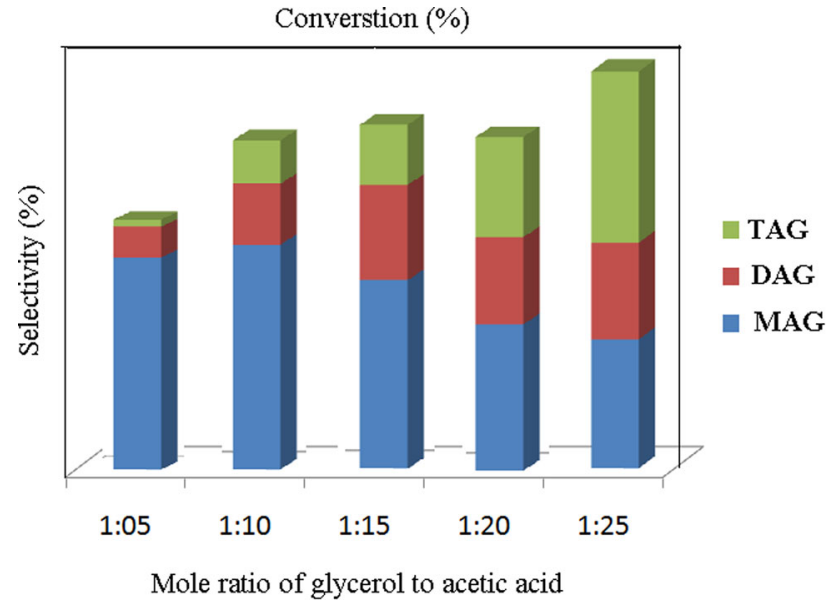

Fig. 6 Acetylation of glycerol over different mole ratio of substrate and reactant

RHS-Al) shown the $100 \%$ conversion for catalytic glycerol conversion and good product selectivity obtained towards diacetin and triacetin formation (Table 4). Figure 6 shows the pictorial representation of glycerol conversation and clear image of selectivity towards triacetin formation at higher mole ratio of substrate to reactant. One can envisage two possible mechanisms [18] for acetylation in strong acidic medium: the first one is the normal AAC2 mechanism, involving protonation of the carbonyl oxygen atom and nucleophilic attack in the carbonyl to form a tetrahedral intermediate, presenting a quaternary carbon atom (Scheme 1); the second mechanism is the AAC1, where protonation takes place in the oxygen atom attached to the carbonyl group, followed by formation of an acylium ion (Scheme 2). The first pathway is normally less energetic, because of the higher stability of the intermediate formed upon protonation in the carbonyl oxygen atom. On the other hand, formation of the tetrahedral intermediate is space demanding, and the second mechanism, involving the acylium ion, prevails in situations of steric constraints [19].

Table 5 shows the comparative catalytic activity of solid catalysts prepared by low cost methodology and conventional route prepared catalyst. The standard solid acid catalyst such as K-10, Niobium phosphate and Amberlyst 15 are shown complete conversion for glycerol acetylation with less selectivity towards triacetin formation. In our case, the prepared bimetallic catalysts like $\mathrm{Ag}-\mathrm{Cu}-$ silicaalumina are showing higher selectivity towards diacetin (DAG) and triacetin (TAG) formation. The DAG and TAG are good additives for fuels such as biodiesel and gasoline due to their role in improve the viscosity. Another advantage of the present work is low cost methodology was adopted to prepare the bimetallic catalysts. The application of triacetin is very much vital for cosmetics formation and also used as additives for petroleum products.

\section{Conclusions}

Rice husk silica-alumina and bimetallic $\mathrm{Ag}-\mathrm{Cu} / \mathrm{RHS}-\mathrm{Al}$ solid acid catalysts were prepared by low cost methodology via sol-gel method and characterized by various physicochemical techniques. Mono, Di, Triacetins are obtained as major products in the presence of $\mathrm{Ag}-\mathrm{Cu} / \mathrm{RHS}-\mathrm{Al}$ catalyst and negligible conversion rate was obtained on raw RHS catalyst. The rod like aggregated particle morphology obtained for $\mathrm{Ag}-\mathrm{Cu} / \mathrm{RHS}-\mathrm{Al}$ catalyst. $\mathrm{Ag}-\mathrm{Cu}$ modified rice husk silica-alumina catalyst shows higher selectivity towards DAG and TAG formation compared to other conventional catalysts. Conversion and selectivity for 
Scheme 1 Acetylation mechanism with formation of a tetrahedral intermediate

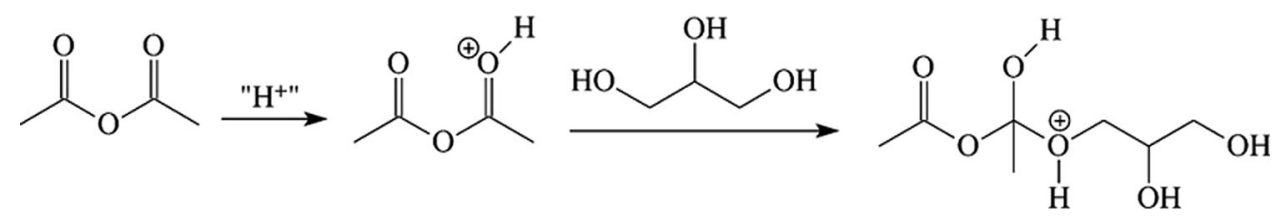

Tetrahedral intermediate

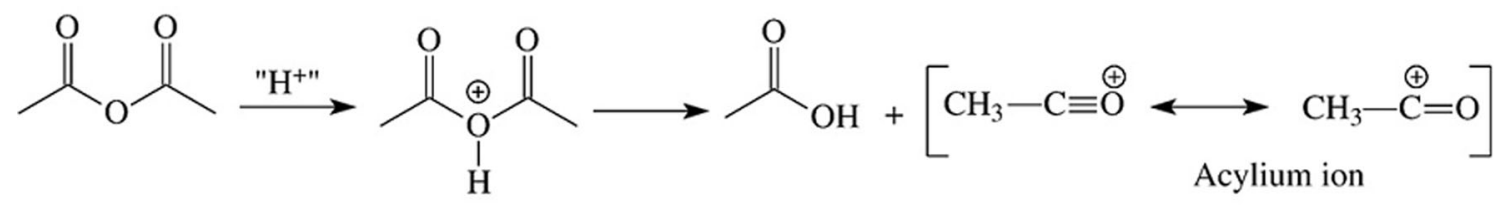<smiles>CC(=O)OCC(O)CO</smiles>

Scheme 2 Acetylation mechanism with formation of an acylium ion

Table 5 Comparison of catalytic activity of various catalyst for glycerol acetylation

\begin{tabular}{lcccl}
\hline Catalyst & Conversion (\%) & \multicolumn{3}{c}{ Selectivity (\%) } \\
\cline { 3 - 5 } & & MAG & DAG & TAG \\
\hline RHS-Al $^{\#}$ & 76.8 & 89.4 & 10.6 & - \\
$10 \mathrm{Cu} / \mathrm{RHS}-\mathrm{Al}^{\#}$ & 83.8 & 68.3 & 21.1 & 10.6 \\
$1 \mathrm{Ag} 10 \mathrm{Cu} / \mathrm{RHS}-\mathrm{Al}^{\#}$ & 97.5 & 3.7 & 58.4 & 37.9 \\
$5 \mathrm{Ag} 10 \mathrm{Cu} / \mathrm{RHS}-\mathrm{Al}^{\#}$ & 100 & 2.4 & 46.3 & 51.3 \\
H-Beta* & 94 & 48 & 39 & 4 \\
K-10* & 94 & 36 & 52 & 6 \\
Niobium phosphate* & 94 & 38 & 49 & 7 \\
Amberlyst-15* & 97 & 18 & 55 & 24 \\
\hline
\end{tabular}

* Ref. [17] Molar ratio glycerol to acetic acid $=1: 4$, reaction temperature is $393 \mathrm{~K}$ and reaction time $2 \mathrm{~h}$

\# Mole ratio of glycerol to acetic acid $=1: 10$, reaction temperature is $393 \mathrm{~K}$ and reaction time $5 \mathrm{~h}$

glycerol acetylation reaction are improved greatly due to nature of active centers exists on bimetallic-rice husk silica catalyst.

Acknowledgments The research project was financially supported by King Saud University, Deanship of Scientific Research, Research Chairs.

Authors Contributions RJ performed all experiments, processed data, initial data analysis and first draft of manuscript; HAA guidance, TR secondary data analysis, subsequent drafts of manuscript FA, guidance, THD project design. All authors have read and approved the final manuscript.

Open Access This article is distributed under the terms of the Creative Commons Attribution 4.0 International License (http://crea tivecommons.org/licenses/by/4.0/), which permits unrestricted use, distribution, and reproduction in any medium, provided you give appropriate credit to the original author(s) and the source, provide a link to the Creative Commons license, and indicate if changes were made.

\section{References}

1. Dasari MA, Kiatsimkul P-P, Sutterlin WR, Suppes GJ (2005) Appl Catal A Gen. 281:225

2. Maris EP, Ketchie WC, Murayama M, Davis RJ (2007) J Catal 251:281

3. Feng J, Fu HY, Wang JB, Li RX, Chen H, Li XJ (2008) Catal Commun 9:1458

4. Runeberg J, Baiker A, Kijenski J (1985) Appl Catal. 17:309

5. Montassier C, Giraud D, Barbier J (1988) In: Guisnet M, Barrault J, Bouchoule C, Dupres D, Montassier C, Pérot G (eds.) Stud. Surf. Sci. Catal. Amsterdam: Elsevier, pp. 165

6. Mat R, Amin NAS, Ramli Z, Abu Bakar WA (2006) J Nat Gas Chem 15: 259

7. Karinen RS, Krause AOI (2003) Appl Catal A Gen. 306:128

8. Wessendorf R, Erdoel Kohle (1995) Erdgas Petrochemie 48: 138

9. Klepacova K, Mravec D, Bajus M (2005) Appl Catal A 294:141

10. Reddy PS, Sudarsanamm P, Raju G, Reddy BM (2012) J Indus Eng Chem. 18:648

11. Nomura S, Hyoshi T (1995) JP patent 203429

12. Lipkowski AW, Kijenski J, Walisiewicz-Niedbalska N (2005) Pol Chemik 58:238 
13. Taguchi Y, Oishi A, Ikeda Y, Fujita K, Masuda T (2000) JP patent 298099

14. Adam F, Radhika T (2010) Chem Eng J 160:249

15. Muruvvet Y, Mehmet A, Tonbul Y, Kadir Y (1999) Turk J Chem 23:319

16. Fillipe AC Garcia, Valdeilson S. Braga, Júnia CM Silva, José A. Dias, Sílvia CL Dias, Jorge LB Davo (2007) Catal Lett 119:101

17. Silva LN, Gonçalves VLC, Mota CJA (2010) Catal Commun 11:1036
18. Lowry TH, Richardson KS (1981) Mechanism and theory in organic chemistry, 2nd edn. Harper and Row, New York, pp 652-658

19. Bender ML, Ladenheim H, Chen MC (1961) J Am Chem Soc 83:123-127

20. Bagheri S, Muhd Julkapl N, Yehye WA (2015) Renew Sustain Energy Rev 41:113-127 